\title{
GEOTECNOLOGIAS APLICADAS AO ZONEAMENTO AGROECOLÓGICO DO ESTADO DO MATO GROSSO DO SUL
}

\section{Geotechnologies applied for Agroecological Zoning of the Mato Grosso do Sul State (Brazil)}

Silvio Barge Bhering Empresa Brasileira de Pesquisa Agropecuária / Embrapa Solos, Rio de Janeiro, Brasil. silvio.bhering@embrapa.br

César da Silva Chagas Embrapa Solos, Rio de Janeiro, Brasil. cesar.chagas@embrapa.br

Waldir Carvalho Junior Embrapa Solos, Rio de Janeiro, Brasil. waldir.carvalho@embrapa.br

Nilson Rendeiro Pereira Embrapa Solos, Rio de Janeiro, Brasil. nilson.pereira@embrapa.br

Fernando Cézar Saraiva Amaral Embrapa Solos, Rio de Janeiro, Brasil. fernandocezar.amaral@embrapa.br

Maria José Zaroni

Embrapa Solos, Rio de Janeiro, Brasil. maria.zaroni@embrapa.br Alexandre Ortega Gonçalves Embrapa Solos, Rio de Janeiro, Brasil. alexandre.ortega@embrapa.br

Artigo recebido em 22/08/2012 e aceito para publicação em 19/03/2013

RESUMO: O trabalho teve como objetivo apresentar uma proposta metodológica para o zoneamento agroecológico do Estado do Mato Grosso do Sul, tendo como estudo de caso o município de Bandeirantes. Foram utilizadas geotecnologias, tais como: imagens de satélite (Landast 5), sistema de posicionamento global, sistemas de informação geográfica, cartografia digital e software de processamento digital de imagens, visando construir parâmetros ambientais para uma análise integrada de dados, associados com atributos do terreno derivados de um modelo digital de elevação, dados de propriedades dos solos e de clima. Estas geotecnologias foram empregadas para calcular e espacializar o potencial natural de erosão das terras, a fertilidade natural, drenagem interna e a capacidade de retenção de umidade dos solos. A análise integrada dos parâmetros ambientais, do uso atual das terras e da espacialização da legislação ambiental, 
permitiu estratificar o município em diferentes zonas agroecológicas recomendadas para o uso agrícola; para o uso com pastagens; para a conservação dos recursos naturais e para a recuperação ambiental. No município de Bandeirantes as zonas agroecológicas recomendadas para o uso com lavouras somam 1.150 $\mathrm{km}^{2}(37 \%)$ e para pastagens $1.658 \mathrm{~km}^{2}(53 \%)$, As recomendadas para conservação dos recursos naturais e para recuperação ambiental correspondem a $310 \mathrm{~km}^{2}$, isto é, $10 \%$ das terras do município. Pôde-se concluir que a análise integrada de dados ambientais associados às geotecnologias possibilitou a avaliação quantitativa e qualitativa permitindo à estratificação do município em diferentes zonas agroecológicas com indicação de áreas passíveis de exploração agrícola sustentável

Palavras chave: ordenamento de uso e ocupação das terras; planejamento agrícola; geomática; geotecnologia.

ABSTRACT: This study aimed to present the methodological approach of the agroecological zoning of Mato Grosso do Sul State. The approach incorporated quantitative and qualitative assessment, with geotechnologies (satellite image-landsat 5, global positioning system, geographic information system, digital mapping, software of digital image processing) adoption to perform an integrated analysis of environmental data. Primary soils information associated with terrain attributes and climate characteristics were used with geotechnologies to evaluation of the natural erosion potential, natural fertility, internal drainage and moisture soil retention capacity of soil. The land use, and land cover and the environmental laws were observed. The integrated analysis of these data allowed environmental stratification in different agroecological zones. These zones are defined to agricultural use; pastures; conservation of natural resources or ecological restoration. In Bandeirantes case study, the agroecological zones recommended for agriculture sum $1,150 \mathrm{~km}^{2}$. The evaluation for conservation of natural resources and ecological results in $310 \mathrm{~km}^{2}$, and for the areas recommended for pastures sum 1,650 $\mathrm{km}^{2}$ or $53 \%$ of Bandeirantes municipality. This study allows conclude that the integrated analysis of environmental data with application of geotechnologies can subsidize a quantitative and qualitative assessment, stratifying the lands in different agroecological zones, each one with recommendations for sustainable use, and contributing as a powerful tool for spatial planning.

Keywords: Environmental planning; Land use. Geotechnologies; Geomatic.

\section{INTRODUÇÃO}

Ao longo das últimas três décadas a produtividade da agropecuária brasileira cresceu vertiginosamente, mas também incorporou ao processo produtivo solos considerados "marginais" em ambientes frágeis. Com o acirramento da dicotomia entre o desenvolvimentismo e a preservação ambiental, esforços têm sido realizados no sentido do planejamento de uso e ocupação sustentável das terras. No entanto, o uso sustentável dos agroecossistemas requer a formulação de modelos de desenvolvimento conservacionistas, compreendendo um conjunto de práticas de conservação do solo, da água e da biodiversidade, analisados de forma integrada.

De acordo com a FAO (2005), uma abordagem integrada é necessária para aumentar a capacidade dos países para planejar e monitorar melhor o uso e manejo de seus recursos naturais, de modo a possibilitar o aumento da produtividade agrícola, ao mesmo tempo em que preserva o recurso solo e se mantém a qualidade ambiental. Nessa busca, os zoneamentos aparecem como um excelente instrumento de planejamento, visto que, os recursos naturais essenciais (solo e água) estão declinando em quantidade e qualidade devido à competição com as demandas industriais e urbanas, além da degradação e a poluição (FAO, 1996).

A FAO tem feito considerável progresso nas últimas décadas aplicando e disseminando ferramentas para a avaliação e utilização do potencial da terra para uma agricultura sustentável. Estas ferramentas incluem os sistemas de informação dos recursos da terra baseados em softwares de Sistemas de Informações Geográficas (SIG), integrando os modelos de zoneamento agroecológico (FAO, 2005). Neste sentido, a integração de grandes quantidades de dados ambientais e socioeconômicos, comum nesses tipos de estudos é uma tarefa complexa.

Vários trabalhos têm demonstrado a importância da utilização de geotecnologias nestes estudos. De 
acordo com Rosa (2005), geotecnologias integram um conjunto de tecnologias para coleta, processamento, análise e oferta de informação com referência geográfica. As geotecnologias são compostas por soluções de hardware, software e peopleware que juntas constituem poderosas ferramentas para a tomada de decisão. Dentre as geotecnologias destacam-se a cartografia digital, o sensoriamento remoto, os sistemas de posicionamento global (GPS), a topografia georreferenciada, e em especial, os sistemas de informação geográfica, importantes para a integração desses dados.

Geotecnologias foram utilizadas por Martorano et al. (1999) no zoneamento agroecológico da quadrícula de Ribeirão Preto, SP, tendo como base características de solo, relevo e clima. Por sua vez, Chagas et al. (2001) e Carvalho Junior et al. (2003) integraram variáveis climáticas, pedológicas e da biodiversidade, na elaboração de zoneamentos agropedoclimáticos no Estado do Rio Grande do Sul para as culturas do arroz irrigado e soja, respectivamente. Sans et al. (2001); Maluf et al. (2001); Brunini et al. (2001) e Silva \& Assad (2001) utilizaram sistemas de informação geográfica para integrar dados climáticos quantitativos e modelos probabilísticos.

Calderano Filho et al. (2010) combinaram técnicas de mapeamento digital, produtos de sensoriamento remoto e modelo digital de elevação (MDE), por meio da utilização do geoprocessamento, no planejamento geoambiental de paisagens rurais montanhosas ocupadas com agricultura familiar na Serra dos Órgãos, no Estado do Rio de Janeiro. Os resultados obtidos permitiram discriminar e caracterizar aspectos físicos e ecológicos dos elementos componentes da paisagem, contribuindo para a melhor compreensão dos recursos ambientais com suas potencialidades e limitações.

Outras abordagens também têm sido aplicadas na elaboração de estudos de avaliação do potencial das terras, como os sistemas especialistas (YIZENGAW \& VERHEYE, 1995; CHAGAS et al., 2006); análise multicritério (ZHANG et al., 2004; BARROS et al., 2007); lógica fuzzy (VAN RANST et al., 1996; BRAI$\mathrm{MOH}$ et al., 2004); e análise multivariada (AGAR et al., 1995; SILVA et al., 2007).

Apesar das diferentes abordagens utilizadas prevalece à visão do zoneamento como instrumento de ordenamento territorial. Assim, o presente estudo tem como objetivo apresentar a metodologia utilizada no Zoneamento Agroecológico do município de Bandeirantes, Estado do Mato Grosso do Sul, que incorpora uma avaliação quantitativa e qualitativa, incluindo análises por meio da utilização de geotecnologias para integração de dados ambientais, oriundos de diferentes fontes e formatos, contribuindo, dessa forma, para a indicação de áreas passíveis de exploração agrícola sustentável.

\section{MATERIAIS E MÉTODOS}

O estudo de caso foi desenvolvido no município de Bandeirantes, localizado na mesorregião centro-norte do Estado do Mato Grosso do Sul (Figura 1 ), entre as coordenadas geográficas $19^{\circ} 31^{\prime} 48^{\prime \prime} \mathrm{S}$ e $53^{\circ} 53^{\prime} 02^{\prime \prime} \mathrm{W}$; $20^{\circ} 07^{\prime} 12^{\prime \prime}$ S e $54^{\circ} 45^{\prime}$ e $36^{\prime \prime} \mathrm{W}$, com área total de $3116 \mathrm{~km}^{2}$. 
Figura 1. Localização do município de Bandeirantes no Estado do Mato Grosso do Sul, evidenciando as Unidades Geoambientais.

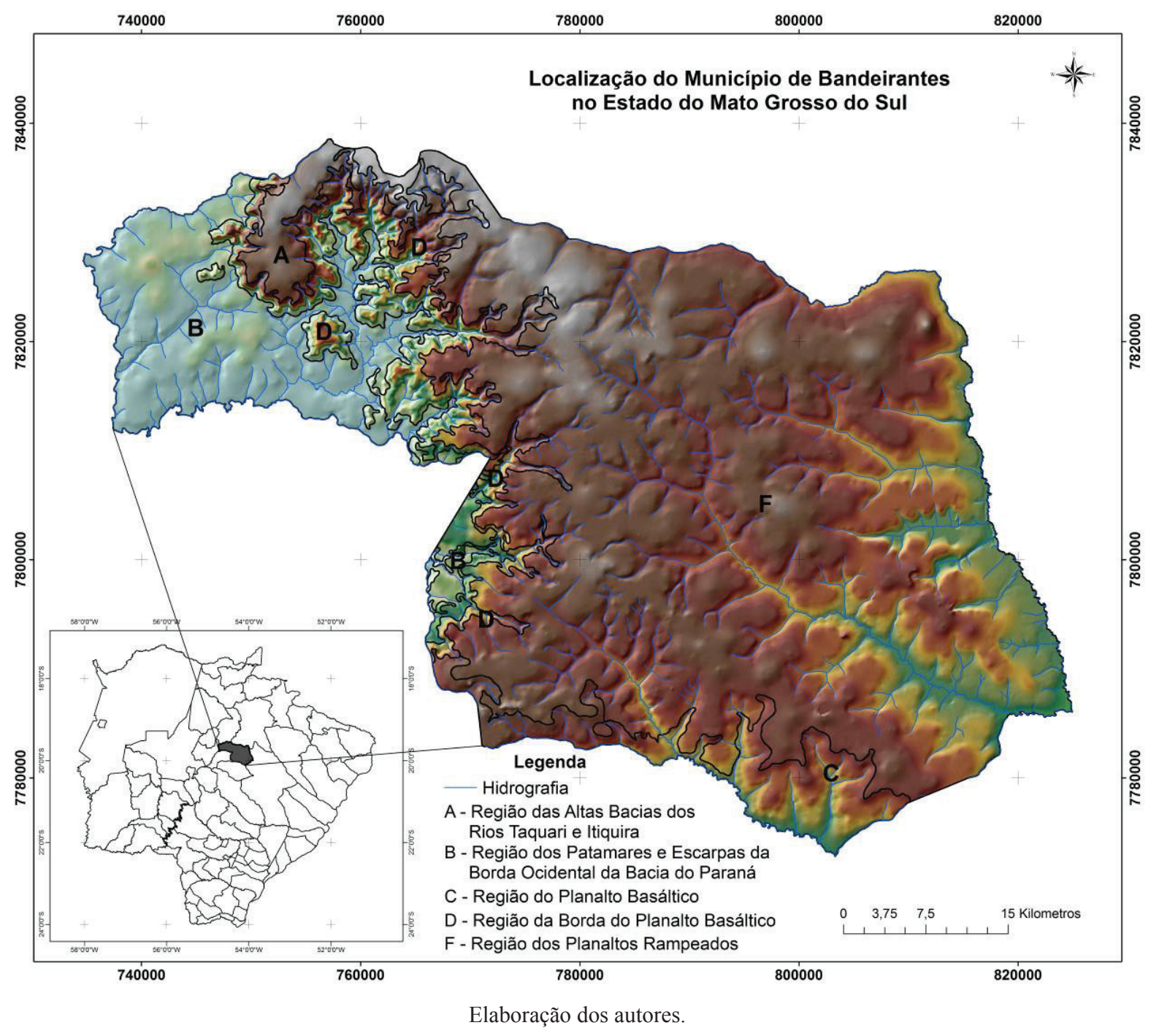

O município apresenta segundo a classificação climática de Köppen, o tipo Aw, caracterizado por um clima tropical, com inverno seco, estação chuvosa no verão, de novembro a abril, e nítida estação seca no inverno, de maio a outubro (julho/agosto são os meses mais secos). A deficiência hídrica anual é de aproximadamente $19 \mathrm{~mm}$, e o excedente hídrico médio ultrapassa $550 \mathrm{~mm}$, isto considerando a CAD (capacidade de água disponível) igual a $100 \mathrm{~mm}$. A temperatura média anual é de $22,3^{\circ}$ e a precipitação pluviométrica de aproximadamente $1655 \mathrm{~mm}$.

De acordo com o Macrozoneamento Geoambiental do Estado de Mato Grosso do Sul (MATO GROSSO DO SUL, 1989), no município de Bandei- rantes ocorrem as seguintes unidades geoambientais: Região dos Patamares e Escarpas da Borda Ocidental da Bacia do Paraná; Região da Borda do Planalto Basáltico, Região das Altas Bacias dos Rios Taquari e Itiquira, Região dos Planaltos Rampeados e Região do Planalto Basáltico (Figura 1).

Inicialmente, foi elaborado o modelo digital de elevação (MDE) da área utilizando-se a opção "topo to raster" do programa ArcGIS Desktop 10 (ESRI, 2010), com resolução espacial de $40 \mathrm{~m}$. O MDE foi gerado a partir de dados relativos às curvas de nível com eqüidistância vertical de $40 \mathrm{~m}$, hidrografia e pontos cotados contidos nas cartas topográficas do DSG, na escala de 1:100.000, no formato digital, referentes 
as folhas Rochedo (SE-21-ZD-V), Camapuã (SE-21ZD-VI), Ribeirão Salgado (SE-22-YC-IV), Jaraguari (SF-21-XB-III) e Ribas do Rio Pardo (SF-22-VA-I) que foram previamente processadas e unidas, dando origem aos planos de informação hidrografia, curvas de nível e pontos cotados.

Durante o pré-processamento da base cartográfica digital, as feições associadas à rede hidrográfica foram editadas no programa Arc/Info, para a obtenção de uma rede de arcos simples, conectados e orientados na direção do escoamento. O plano de informação curvas de nível também foi editado para eliminar os erros tanto de posição geográfica quanto de atributos associados, assegurando a consistência dos dados. Do mesmo modo, os pontos cotados foram checados para eliminar possíveis erros.

Para melhorar a consistência do modelo digital de elevação (MDE), algumas imperfeições foram eliminadas, principalmente aquelas associadas às depressões espúrias, por meio de álgebra de mapas, resultando num MDE hidrologicamente consistido utilizado para gerar dados originais de atributos topográficos como a declividade, a direção do fluxo, o fluxo acumulado e a imagem de sombreamento do relevo, posteriormente empregados nas avaliações.

O processo de estratificação do município de Bandeirantes em zonas agroecológicas foi baseado no conceito de unidade de paisagem (BIRKELAND, 1984), aqui definida como uma entidade espacial na qual a geologia, a geomorfologia, o clima, o solo (tipo, limitações e potencialidades), a vegetação e o tipo de uso do solo, formam um conjunto representativo e homogêneo na paisagem, de acordo com a escala cartográfica adotada e levando em conta a legislação ambiental em vigor. A metodologia de integração das informações utilizada neste estudo é apresentada na Figura 2.

Figura 2. Diagrama da análise integrada para obtenção das zonas agroecológicas.

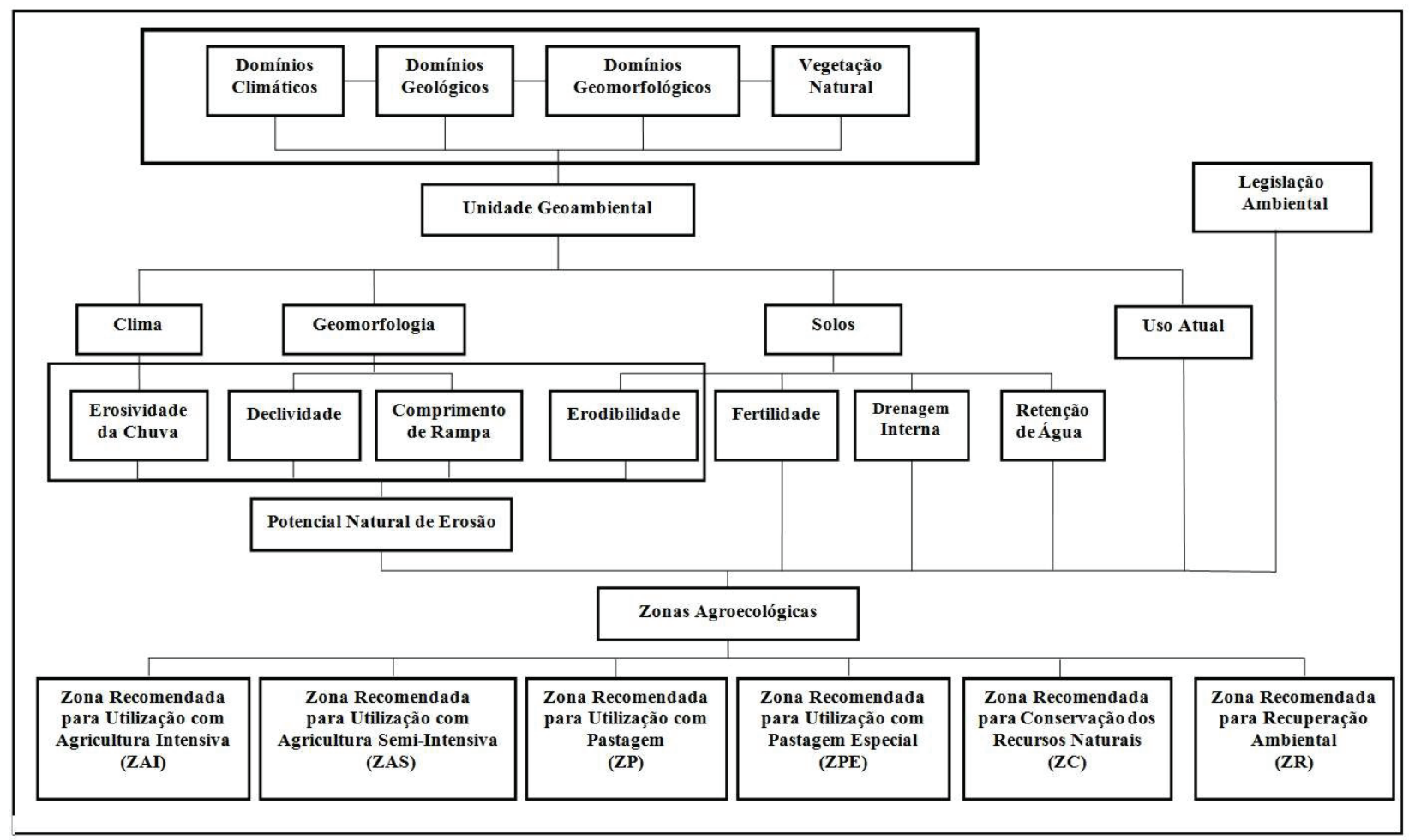

Org. dos autores. 
As Unidades Geoambientais formam o $1^{\circ}$ nível hierárquico da metodologia proposta, sendo, portanto, o de caráter mais generalizado. Estas refletem, de maneira geral, as características geomorfoclimáticas do estado e foram obtidas a partir da integração dos temas: clima, geologia, geomorfologia e vegetação, conforme estabelecido no Macrozoneamento Geoambiental do Estado de Mato Grosso do Sul (MATO GROSSO DO SUL, 1989), complementados por estudos mais recentes (GONÇALVES et al., 2005), e adaptadas ao nível de detalhe deste estudo.

Dados climáticos (temperatura do ar e precipitação pluviométrica) do Estado do Mato Grosso do Sul obtidos em Alfonsi et al. (2006) foram utilizados para o cálculo do balanço hídrico (THORNTHWAITE \& MATHER, 1955), considerando $100 \mathrm{~mm}$ a capacidade de armazenamento de água no solo (CAD), da evapotranspiração potencial (EP) (Thornthwaite, 1948), da evapotranspiração real (ER), da deficiência hídrica (DEF) e do excedente hídrico (EXC) para cada ano. Em seguida, estas informações foram processadas para estimar do potencial agroclimático do estado para diferentes culturas anuais e perenes. Os dados de precipitação pluviométrica foram também utilizados no cálculo da erosividade da chuva (fator $\mathrm{R}$ ).
Informações mais detalhadas sobre a geomorfologia do município foram obtidas com a elaboração do mapa de declividade a partir do processamento dos dados originais do modelo digital de elevação (MDE). Esta tem sido considerada um dos mais importantes atributos topográficos primários que controlam os processos pedogenéticos, o potencial de erosão/ deposição, e muitos outros processos importantes (GALLANT \& WILSON, 2000).

Os dados de solos foram obtidos no levantamento de reconhecimento de baixa intensidade dos solos do Município de Bandeirantes (EMBRAPA, 2009), na escala 1:100.000, elaborado para a realização desse trabalho. Com base nas características ambientais das unidades taxonômicas componentes das unidades de mapeamento e dos respectivos perfis representativos destas unidades foram elaborados os mapas de fertilidade natural, drenagem interna e capacidade de retenção de água no solo, por meio da conversão do formato vetorial para o formato raster. Os critérios utilizados na definição das classes de fertilidade, drenagem e retenção de água dos solos, utilizadas nos respectivos mapas, foram extraídos de Ramalho Filho \& Beek (1995), Embrapa (2000), Sans et al. (2001) e Embrapa (2006), e que são resumidamente apresentados no Quadro 1.

Quadro 1. Classes de drenagem, fertilidade e retenção de água dos solos considerados.

\begin{tabular}{|c|c|c|c|}
\hline Valor & Drenagem & Fertilidade & Retenção de água (50 cm) \\
\hline 1 & Boa & $\begin{array}{c}\text { Elevada }(\mathrm{V} \geq 60 \%, \mathrm{~S} \geq 6 \mathrm{cmolc} / \mathrm{kg} \text { e condutividade } \\
\text { elétrica }<4 \mathrm{dSm}-1)\end{array}$ & $\begin{array}{c}\text { Alta }-\mathrm{CAD} \geq 60 \mathrm{~mm} \\
\left.\text { (solos tipo } 3^{*}\right)\end{array}$ \\
\hline 2 & Moderada & $\begin{array}{c}\text { Média }(\mathrm{V} \geq 35 \mathrm{e}<60 \%, \mathrm{~S} \geq 4 \mathrm{e}<6 \mathrm{cmolc} / \mathrm{kg} \text { e condu- } \\
\text { tividade elétrica }<4 \mathrm{dSm}-1)\end{array}$ & $\begin{array}{c}\text { Moderada } \\
\text { CAD } \geq 40 \mathrm{e}<60 \mathrm{~mm} \\
\left(\text { solos tipo } 2^{*}\right)\end{array}$ \\
\hline 3 & Imperfeita & $\begin{array}{c}\text { Baixa }(\mathrm{V} \geq 10 \mathrm{e}<35 \%, \mathrm{~S} \geq 2 \mathrm{e}<4 \mathrm{cmolc} / \mathrm{kg}, \text { conduti- } \\
\text { vidade elétrica } \geq 4 \mathrm{e}<7 \mathrm{dSm}-1 \mathrm{e} \% \text { argila }<15 \%)\end{array}$ & $\begin{array}{c}\text { Baixa } \\
\text { CAD } \geq 20 \mathrm{e}<40 \mathrm{~mm} \\
(\text { solos tipo } 1)^{*}\end{array}$ \\
\hline 4 & $\begin{array}{c}\text { Mal Drena- } \\
\text { do }\end{array}$ & $\begin{array}{c}\text { Muito Baixa }(\mathrm{V} \leq 10 \%, \mathrm{~S}<2 \mathrm{cmolc} / \mathrm{kg} \text { e } \% \text { argila } \\
<15 \% \text { e/ou saturação por sódio } \geq 15 \% \text { e } / \text { ou conduti- } \\
\text { vidade elétrica } \geq 7 \mathrm{dSm}-1)\end{array}$ & $\begin{array}{c}\text { Muito baixa } \\
\text { CAD }<20 \mathrm{~mm} \\
\text { (solos tipo } 1 *)\end{array}$ \\
\hline
\end{tabular}

V - Saturação por Bases; S - Soma de Bases; CAD - Capacidade de Armazenamento de Água no Solo. *classificação retirada do zoneamento de risco climático do Ministério da Agricultura. 
Complementando a avaliação foi estimado o risco potencial de degradação do ambiente natural relacionada à erosão do solo (potencial natural de erosão-PNE), que os solos apresentam (Quadro 2).

Quadro 2. Classes de potencial natural de erosão.

\begin{tabular}{|c|c|c|}
\hline Valor & Classe & Potencial natural de erosão (t ha-1 ano-1) \\
\hline 1 & Baixa & $<10$ \\
\hline 2 & Moderada & $10-50$ \\
\hline 3 & Alta & $50-200$ \\
\hline 4 & Muito alta & $>200$ \\
\hline
\end{tabular}

Fonte: adaptado de FAO (1967). Org. dos autores.

O PNE foi definido por meio dos termos da Equação Universal de Perda de Solo (EUPS) proposta por Wischmeier \& Smith (1978), considera apenas os fatores que representam os parâmetros do meio físico e corresponde às estimativas de perdas de solos em áreas destituídas de vegetação natural e sem intervenção antrópica, sendo definido pela equação 1 .

$$
P N E=R K L S
$$

onde: $\mathrm{PNE}=$ potencial natural de erosão (t ha$\left.{ }^{-1} \mathrm{ano}^{-1}\right) ; \mathrm{R}=$ fator erosividade da chuva $\left(\mathrm{MJ} \mathrm{mm} \mathrm{ha}{ }^{-1} \mathrm{~h}^{-1}\right.$ $\left.\mathrm{ano}^{-1}\right) ; \mathrm{K}=$ fator erodibilidade do solo $\left(\mathrm{t} \mathrm{h} \mathrm{MJ}^{-1} \mathrm{~mm}^{-1}\right)$; $\mathrm{L}$ = fator comprimento de rampa (adimensional); e $\mathrm{S}$ $=$ fator declividade (adimensional).

A erosividade da chuva foi estimada com base na equação desenvolvida por Lombardi Neto \& Moldenhauer (1992), que por sua vez, utiliza registros pluviométricos como médias mensais e anuais de chuva a partir do coeficiente de Fournier (FOURNIER, 1960) modificado por Lombardi Neto (1977). O valor de erosividade estimado para o município foi de 7601 MJ mm.ha- ${ }^{-1} \cdot \mathrm{h}^{-1} \cdot$ ano $^{-1}$ (ZARONI et al., 2007).

$\mathrm{O}$ fator de erodibilidade dos solos foi estimado pelo método indireto, através da utilização da equação 2, conforme utilizado por Mannigel (2002) na estimativa da erodibilidade dos solos de São Paulo.

Fator K $=((\%$ areia $+\%$ silte $) /(\%$ argila $)) / 100$

$\mathrm{O}$ fator $\mathrm{K}$ foi calculado para cada componente de unidade de mapeamento, com base nos dados de perfis representativos das classes de solos identificadas no município, considerando a média ponderada dos subhorizontes até uma profundidade de $100 \mathrm{~cm}$. Visto que as unidades de mapeamento estabelecidas possuem até três componentes foi obtido um fator $\mathrm{K}$ para cada uma destas unidades, por meio do cálculo da média ponderada, levando-se em conta à proporção que cada componente tem na unidade de mapeamento.

O fator LS, por sua vez, foi obtido utilizando-se uma rotina adaptada desenvolvida por Engel (1999), conforme a equação 3.

Fator LS $=\operatorname{Pow}(([$ flowacc $] * 40 / 22.13), 0.4) * \operatorname{Pow}((\mathrm{S}$ in([slopedg]*3.14/180)/0.0896), 1.3))

onde, Pow = função de potenciação; flowacc = grid fluxo acumulado; $\operatorname{Sin}=$ função seno; slopedg $=$ declividade em graus.

Outra importante informação para o zoneamento agroecológico é o mapa de uso e cobertura das terras, elaborado a partir de imagens do sensor TM Landsat 5, órbitas/ponto 225/73, 225/74 e 224/74, todas de fevereiro de 2010.

Para identificação dos tipos de uso e cobertura vegetal das terras foi realizada uma classificação supervisionada utilizando o software de processamento de imagens ENVI versão 4.2. As classes de uso e cobertura identificadas foram: vegetação natural, que engloba áreas com vegetação primária e vegetação secundária em vários estágios e de diferentes tipos; 
culturas anuais e perenes; e pastagens em diferentes estágios de degradação (Tabela 3).

Foram também consideradas as áreas especiais representadas pelas unidades de conservação de proteção integral e de uso sustentável e outras porções territoriais que apresentam impedimentos legais e/ou normatização de uso, tais como: as áreas de preservação permanentes (APPs) nas margens dos rios e cursos d'água, ao redor de lagoas e de nas- centes, nas bordas de chapadas e áreas com declividades superiores a $45^{\circ}$ (Quadro 3). A espacialização das APPs localizadas nas margens dos rios e cursos d'água e ao redor de lagoas e de nascentes foi feita por meio da criação de um "buffer", no programa ArcGIS Desktop 10, da hidrografia do município. A largura do "buffer" foi definida pela largura dos rios ou córregos, de acordo com o artigo $2^{\circ}$ da Lei 4.771/65 do código florestal.

Quadro 3. Classes de uso atual e legislação ambiental considerados.

\begin{tabular}{|c|c|c|}
\hline Valor & Uso Atual & Legislação Ambiental \\
\hline 1 & Vegetação Natural & $\begin{array}{c}\text { Unidades de conservação, áreas de preservação permanentes, bordas de chapadas } \\
\text { e áreas com declividades superiores a } 45^{\circ}\end{array}$ \\
\hline 2 & Lavouras & Demais áreas \\
\hline 3 & Pastagens & - \\
\hline
\end{tabular}

Org. dos autores.

Os parâmetros utilizados na definição das zonas agroecológicas são baseados na combinação das condições climáticas, geomorfológicas, pedológicas e de uso e cobertura das terras que interferem no desenvolvimento e produção sustentáveis das culturas agrícolas, e nos sistemas de manejo em que estas se desenvolvem. Desta maneira, cada unidade representa um conjunto de características, limitações e potencialidades estratificadas em 6 zonas agroecológicas: ZAI - zonas recomendadas para agricultura intensiva; ZAS - zonas recomendadas para agricultura semi-intensiva; ZP - zonas recomendadas para utilização com pastagens; ZPE - zonas recomendadas para utilização com pastagens adaptadas às condições de excesso de umidade; ZC - zonas recomendadas para conservação dos recursos naturais; e ZR - Zonas recomendadas para recuperação ambiental.

Para a geração do mapa das zonas agroecológicas, as interpretações foram implementadas na forma de uma álgebra de mapas, utilizando-se o programa ArcGIS Desktop 10, conforme a equação 4:

zonas $=\operatorname{con}(([\mathrm{pne}]==4)$ and $([$ uso_atual $]==2)$ or $([$ apps $]==1)$ and ([uso_atual] $==2), 42$, con $(([$ pne $]$ $==4)$ and ([uso_atual] $==1)$ or $([\operatorname{apps}]==1)$ and ([uso_atual] $==1), 41$, con $(([$ dren $]>=3), 32$, con $(([\mathrm{pne}]==3)$ or $([$ fert $]==4)$ or $([$ ret_agua $]>=3), 31$, con $(([$ pne $]==2)$ and $([$ fert $]<=3)$ and $([$ dren $]<=2)$ and $([$ ret_agua $]<=2), 2,1))))$ )

onde: pne - grid de potencial natural de erosão; uso_atual - grid de uso atual das terras; apps - grid de legislação ambiental; dren - grid de drenagem interna dos solos; fert - grid de fertilidade dos solos; ret_agua - grid de retenção de umidade dos solos. Os números representam os valores apresentados nas Tabelas 1, 2 e 3 .

Finalmente, nas zonas recomendadas para o uso com agricultura (intensiva e semi-intensiva) foi feita uma avaliação da aptidão para diferentes culturas, adequada a melhor opção de uso conforme Embrapa (2000), em função, principalmente, das exigências climáticas das culturas.

\section{RESULTADOS E DISCUSSÃO}

A metodologia adotada estratificou o município em um primeiro nível, de acordo com as Unidades Geoambientais, e em segundo nível, cada Unidade Geoambiental foi subdividida em unidades mais homogêneas, em uma combinação única de características, limitações e potencialidades para o uso das terras, denominadas Zonas Agroecológicas, obtidas a partir das informações derivadas de solos e relevo (Figura 3 ), conforme as regras apresentadas no Quadro 4. 
Geotecnologias aplicadas ao zoneamento agroecológico do estado do Mato Grosso do Sul Silvio Barge Bhering, Cesar Chagas da Silva, Waldir Carvalho Junior, Nilson Rendeiro Pereira, Fernando Cézar Saraiva Amaral, Maria José Zaroni, Alexandre Ortega Gonçalves

Figura 3. Informações temáticas utilizadas na definição das zonas agroecológicas.
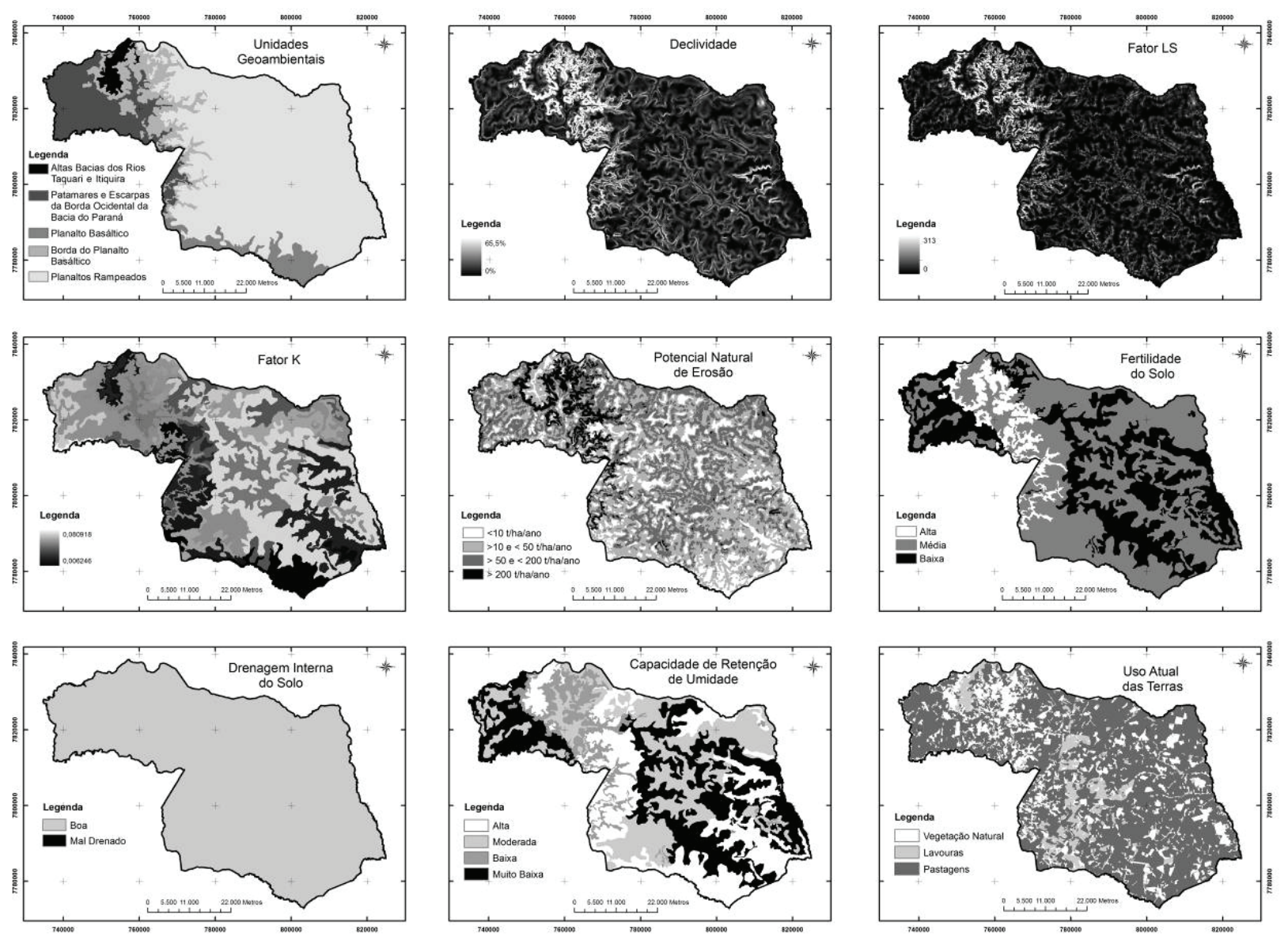

Elaboração dos autores. 
Geotecnologias aplicadas ao zoneamento agroecológico do estado do Mato Grosso do Sul

Silvio Barge Bhering, Cesar Chagas da Silva, Waldir Carvalho Junior, Nilson Rendeiro Pereira, Fernando Cézar Saraiva Amaral, Maria José Zaroni, Alexandre Ortega Gonçalves

Quadro 4. Características das zonas agroecológicas.

\begin{tabular}{|c|c|c|c|c|c|c|}
\hline \multirow[b]{2}{*}{ Zonas } & \multicolumn{6}{|c|}{ Características } \\
\hline & $\begin{array}{c}\text { PNE } \\
\left(\mathrm{t} \mathrm{ha}^{-1} \mathrm{ano}^{-1}\right)\end{array}$ & $\begin{array}{c}\text { Uso Atual das } \\
\text { Terras }\end{array}$ & $\begin{array}{l}\text { Legislação } \\
\text { Ambiental }\end{array}$ & Fertilidade & $\begin{array}{l}\text { Retenção de } \\
\text { Água }\end{array}$ & $\begin{array}{l}\text { Drenagem do } \\
\text { Solo }\end{array}$ \\
\hline ZAI & $<10$ & $\begin{array}{c}\text { Não } \\
\text { Utilizado }\end{array}$ & $\begin{array}{c}\text { Não } \\
\text { Utilizado }\end{array}$ & $\begin{array}{l}\text { Alta, Média } \\
\text { ou Baixa }\end{array}$ & $\begin{array}{l}\text { Alta ou Mode- } \\
\text { rada }\end{array}$ & $\begin{array}{c}\text { Boa ou Mode- } \\
\text { rada }\end{array}$ \\
\hline ZAS & $>10$ e $<50$ & $\begin{array}{c}\text { Não } \\
\text { Utilizado }\end{array}$ & $\begin{array}{c}\text { Não } \\
\text { Utilizado }\end{array}$ & $\begin{array}{l}\text { Alta, Média } \\
\text { ou Baixa }\end{array}$ & $\begin{array}{c}\text { Alta ou Mode- } \\
\text { rada }\end{array}$ & $\begin{array}{c}\text { Boa ou Mode- } \\
\text { rada }\end{array}$ \\
\hline $\mathrm{ZP}$ & $>50$ e $<200$ & $\begin{array}{c}\text { Não } \\
\text { Utilizado }\end{array}$ & $\begin{array}{c}\text { Não } \\
\text { Utilizado }\end{array}$ & $\begin{array}{c}\text { Baixa ou } \\
\text { Muito Baixa }\end{array}$ & $\begin{array}{l}\text { Baixa ou Mui- } \\
\text { to Baixa }\end{array}$ & $\begin{array}{c}\text { Boa, Modera- } \\
\text { da ou Imper- } \\
\text { feita }\end{array}$ \\
\hline ZPE & $<10$ & $\begin{array}{c}\text { Não } \\
\text { Utilizado }\end{array}$ & $\begin{array}{c}\text { Não } \\
\text { Utilizado }\end{array}$ & $\begin{array}{c}\text { Não } \\
\text { Utilizado }\end{array}$ & Não Utilizado & Mal drenado \\
\hline $\mathrm{ZC}$ & $>200$ & $\begin{array}{l}\text { Vegetação } \\
\text { Natural }\end{array}$ & $\begin{array}{c}\text { Unidades de } \\
\text { Conservação } \\
\text { e/ou Áreas } \\
\text { de Proteção } \\
\text { Permanente }\end{array}$ & $\begin{array}{c}\text { Não } \\
\text { Utilizado }\end{array}$ & Não Utilizado & $\begin{array}{c}\text { Não } \\
\text { Utilizado }\end{array}$ \\
\hline ZR & $>200$ & $\begin{array}{c}\text { Lavouras ou } \\
\text { Pastagem }\end{array}$ & $\begin{array}{c}\text { Unidades de } \\
\text { Conservação } \\
\text { e/ou Áreas } \\
\text { de Proteção } \\
\text { Permanente }\end{array}$ & $\begin{array}{c}\text { Não } \\
\text { Utilizado }\end{array}$ & Não Utilizado & $\begin{array}{c}\text { Não } \\
\text { Utilizado }\end{array}$ \\
\hline
\end{tabular}

ZAI - zonas recomendadas para agricultura intensiva; ZAS - zonas recomendadas para agricultura semi-intensiva; ZP - zonas recomendadas para utilização com pastagens; ZPE - zonas recomendadas para utilização com pastagens adaptadas às condições de excesso de umidade;

ZC - zonas recomendadas para conservação dos recursos naturais; e ZR - Zonas recomendadas para recuperação ambiental.

Org. dos autores.

Esse método possibilitou a identificação e o delineamento de 98 subzonas agroecológicas no município de Bandeirantes (Figura 4), identificadas por suas peculiaridades na produção e na produtividade dos cultivos. 
Figura 4. Mapa das subzonas agroecológicas do Município de Bandeirantes

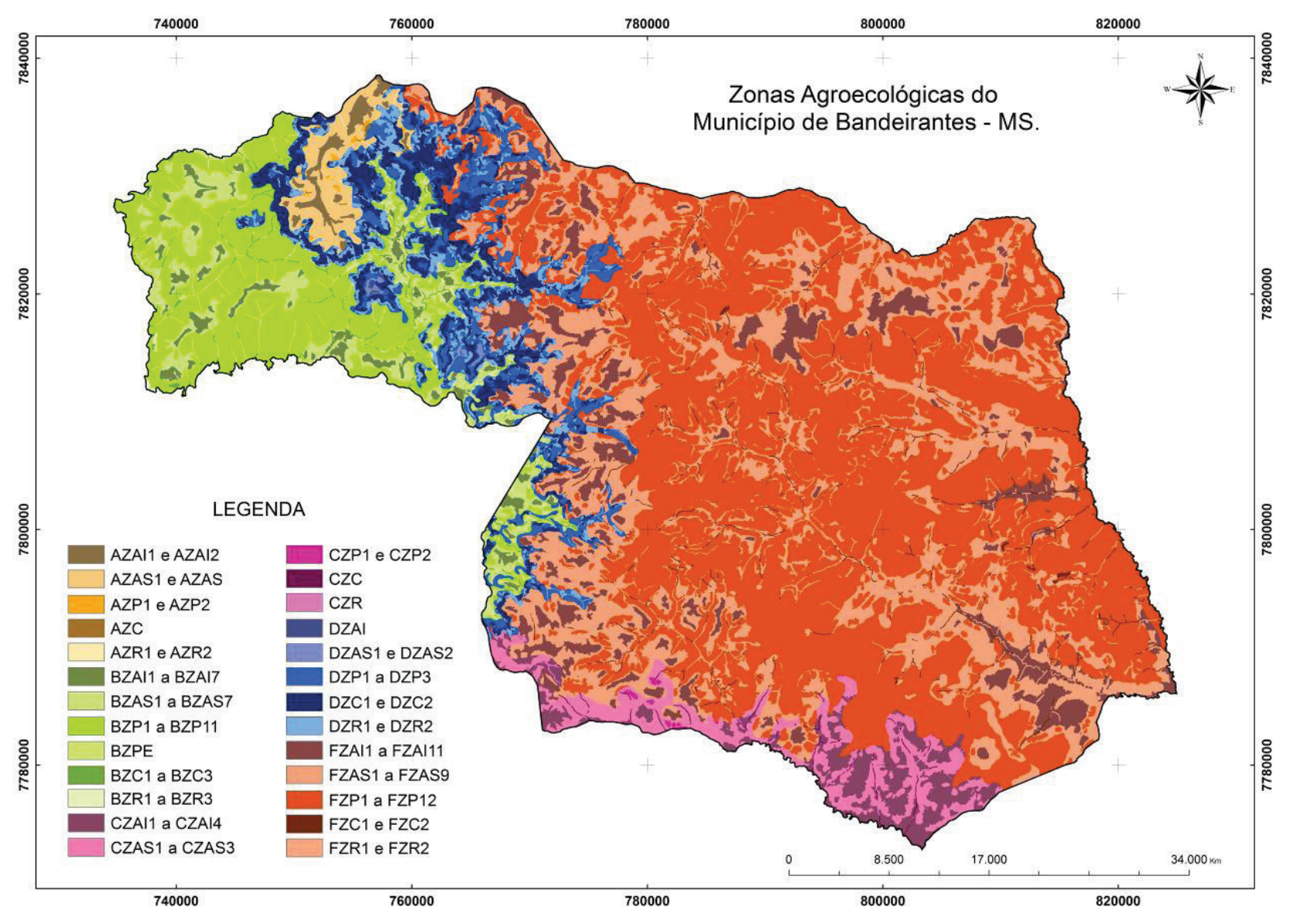

Elaboração dos autores.

A distribuição percentual das zonas agroeco-

lógicas no município é apresentada na Tabela 5. 
Geotecnologias aplicadas ao zoneamento agroecológico do estado do Mato Grosso do Sul

Silvio Barge Bhering, Cesar Chagas da Silva, Waldir Carvalho Junior, Nilson Rendeiro Pereira, Fernando Cézar Saraiva Amaral,

Maria José Zaroni, Alexandre Ortega Gonçalves

Tabela 5. Distribuição e ocorrência das subzonas agroecológicas no Município de Bandeirantes.

\begin{tabular}{|c|c|c|c|c|c|c|c|c|}
\hline Zonas & Área (ha) & $\%$ & Zonas & Área (ha) & $\%$ & Zonas & Área (ha) & $\%$ \\
\hline AZAI1 & 1061,19 & 0,34 & BZP8 & 351,27 & 0,11 & FZAI5 & 1547,11 & 0,50 \\
\hline AZAI2 & 436,23 & 0,14 & BZP9 & 10,95 & 0,00 & FZAI6 & 896,23 & 0,29 \\
\hline AZAS1 & 1303,27 & 0,42 & BZP10 & 1078,31 & 0,35 & FZAI7 & 1944,39 & 0,62 \\
\hline AZAS2 & 2962,95 & 0,95 & BZP11 & 19332,31 & 6,20 & FZAI8 & 476,23 & 0,15 \\
\hline AZC & 48,23 & 0,02 & BZPE & 152,39 & 0,05 & FZAI9 & 3808,47 & 1,22 \\
\hline AZP1 & 24,55 & 0,01 & BZR1 & 21,67 & 0,01 & FZAI10 & 1329,03 & 0,43 \\
\hline AZP2 & 208,71 & 0,07 & BZR2 & 4,55 & 0,00 & FZAI11 & 3099,11 & 0,99 \\
\hline AZR1 & 1,67 & 0,00 & BZR3 & 1516,07 & 0,49 & FZAS1 & 1399,19 & 0,45 \\
\hline AZR2 & 84,23 & 0,03 & CZAI1 & 65,19 & 0,02 & FZAS2 & 3045,99 & 0,98 \\
\hline BZAI1 & 212,87 & 0,07 & CZAI2 & 307,27 & 0,10 & FZAS3 & 1397,51 & 0,45 \\
\hline BZAI2 & 348,71 & 0,11 & CZAI3 & 260,07 & 0,08 & FZAS4 & 8414,55 & 2,70 \\
\hline BZAI3 & 1425,19 & 0,46 & CZAI4 & 6323,67 & 2,03 & FZAS5 & 15299,90 & 4,91 \\
\hline BZAI4 & 568,39 & 0,18 & CZAS1 & 183,11 & 0,06 & FZAS6 & 577,03 & 0,19 \\
\hline BZAI5 & 468,39 & 0,15 & CZAS2 & 2496,23 & 0,80 & FZAS7 & 9787,99 & 3,14 \\
\hline BZAI6 & 182,63 & 0,06 & CZAS3 & 6722,71 & 2,16 & FZAS8 & 4708,87 & 1,51 \\
\hline BZAI7 & 18,15 & 0,01 & $\mathrm{CZC}$ & 405,80 & 0,13 & FZAS9 & 16782,47 & 5,39 \\
\hline BZAS1 & 1017,99 & 0,33 & CZP1 & 143,11 & 0,05 & FZC1 & 103,75 & 0,03 \\
\hline BZAS2 & 166,63 & 0,05 & CZP2 & 41,43 & 0,01 & FZC2 & 2621,49 & 0,84 \\
\hline BZAS3 & 1129,19 & 0,36 & CZR & 374,60 & 0,12 & FZP1 & 669,03 & 0,21 \\
\hline BZAS4 & 1920,15 & 0,62 & DZAI & 62,15 & 0,02 & FZP2 & 416,55 & 0,13 \\
\hline BZAS5 & 4651,27 & 1,49 & DZAS1 & 120,07 & 0,04 & FZP3 & 55,59 & 0,02 \\
\hline BZAS6 & 1156,07 & 0,37 & DZAS2 & 111,11 & 0,04 & FZP4 & 267,43 & 0,09 \\
\hline BZAS7 & 323,11 & 0,10 & DZC1 & 12158,87 & 3,90 & FZP5 & 18608,31 & 5,97 \\
\hline $\mathrm{BZC1}$ & 47,11 & 0,02 & $\mathrm{DZC} 2$ & 30,39 & 0,01 & FZP6 & 16384,70 & 5,26 \\
\hline BZC2 & 20,39 & 0,01 & DZP1 & 10997,75 & 3,53 & FZP7 & 15,27 & 0,00 \\
\hline BZC3 & 1238,40 & 0,40 & DZP2 & 244,23 & 0,08 & FZP8 & 10220,95 & 3,28 \\
\hline BZP1 & 44,55 & 0,01 & DZP3 & 23,11 & 0,01 & FZP9 & 583,43 & 0,19 \\
\hline BZP2 & 17,19 & 0,01 & DZR1 & 7075,83 & 2,27 & FZP10 & 5211,59 & 1,67 \\
\hline BZP3 & 50,15 & 0,02 & DZR2 & 61,43 & 0,02 & FZP11 & 64307,27 & 20,64 \\
\hline BZP4 & 391,59 & 0,13 & FZAI1 & 1755,67 & 0,56 & FZP12 & 12484,23 & 4,01 \\
\hline BZP5 & 2147,35 & 0,69 & FZAI2 & 1504,23 & 0,48 & FZR1 & 389,83 & 0,13 \\
\hline BZP6 & 1266,47 & 0,41 & FZAI3 & 640,71 & 0,21 & FZR2 & 4685,17 & 1,50 \\
\hline BZP7 & 31,59 & 0,01 & FZAI4 & 510,39 & 0,16 & Total & $311.599,87$ & 100,0 \\
\hline
\end{tabular}

Org. dos autores. 
- A - Região das Altas Bacias dos Rios Taquari e Itiquira; B - Região dos Patamares e Escarpas da Borda Ocidental da Bacia do Paraná; C - Região do Planalto Basáltico; D - Região da Borda do Planalto Basáltico; e F - Região dos Planaltos Rampeados.

- ZAI - zonas recomendadas para agricultura intensiva; ZAS - zonas recomendadas para agricultura semi-intensiva; ZP - zonas recomendadas para utilização com pastagens; ZPE - zonas recomendadas para utilização com pastagens adaptadas às condições de excesso de umidade; ZC - zonas recomendadas para conservação dos recursos naturais; e ZR - zonas recomendadas para recuperação ambiental.

- O numeral no final da sigla corresponde à distinção das zonas agroecológicas em função das características dos solos e relevo predominantes.

A Unidade Geoambiental Região das Altas Bacias dos Rios Taquari e Itiquira (A) ocorre exclusivamente na porção noroeste do município, na divisa com o município de São Gabriel do Oeste, ocupando apenas $1,97 \%$ da área total do município. Apresenta uma superfície de topografia constituída por chapadões, onde sedimentos do Terciário recobrem litologias paleozóicas, da Bacia Sedimentar do Paraná (MATO GROSSO DO SUL, 1989). São caracterizados, principalmente, por apresentarem superfícies planas ou suavemente dissecadas com fraca inclinação (declives inferiores a $8 \%$ ), nas quais predominam Latossolos Vermelhos Acriférricos de textura argilosa ou muito argilosa e Latossolos Vermelhos Distróficos de textura argilosa e média. Face às características favoráveis de solos e relevo, a maior parte das terras dessa unidade geoambiental é recomendada para o uso com lavouras, intensivas $(24,42 \%)$ e semi-intensivas $(69,58 \%)$. Neste caso, o predomínio de terras com potencial natural de erosão moderado (10 a $50 \mathrm{t} / \mathrm{ha} /$ ano) é o principal fator determinante do domínio das terras recomendadas para a utilização com lavouras semi-intensivas. A quase totalidade das terras $(80 \%)$ é atualmente explorada com lavouras e pastagens, o que é compatível com o potencial de utilização estimado.

A Unidade Geoambiental Região dos Patamares e Escarpas da Borda Ocidental da Bacia do Paraná (B) é constituída por litologias paleozóicas e mesozóicas, com altimetrias que variam entre 200 e $600 \mathrm{~m}$, individualizada em três compartimentos geomorfológicos: Primeiro Patamar, Depressão Interpatamares e Segundo Patamar (MATO GROSSO DO SUL, 1989). No município de Bandeirantes ocorre apenas o compartimento denominado de Segundo Patamar, esculpido em litologias areníticas da Formação Botucatu, constituindo um desdobramento do relevo cuestiforme com caimento para leste. Nessa unidade predominam os solos classificados como Neossolos Quartzarênicos Órticos e os Latossolos Vermelhos Distróficos de textura média, e em menor proporção, de textura argilosa, normalmente sob condições de relevo plano ou suave ondulado, com declives inferiores a $8 \%$ e alta taxa de utilização agrícola (85\%). No zoneamento as terras dessa unidade foram recomendadas para uso agrícola com pastagens $(60 \%)$, em virtude, principalmente, de sua limitada disponibilidade de nutrientes e de retenção de umidade; e para uso com agricultura semi-intensiva (40\%), associada com os Latossolos Vermelhos de textura mais fina e melhor disponibilidade de nutrientes e de água para as plantas.

Por sua vez, a Unidade Geoambiental da Região do Planalto Basáltico (C) corresponde a uma pequena extensão de terras $\left(173 \mathrm{~km}^{2}\right)$ na sua face sul, fazendo limite com os municípios de Jaraguari e Ribas do Rio Pardo. Está associada com Latossolos Vermelhos Distroférricos (95\%) esculpidos sob litologias basálticas da Formação Serra Geral. Nesta unidade as terras foram recomendadas, quase que integralmente, para agricultura intensiva (40\%) e para agricultura semi-intensiva (54\%), sendo o potencial natural de erosão o principal fator que diferencia essas zonas agroecológicas. O restante da área do município está dividido entre zonas recomendadas para pastagens, zonas de conservação dos recursos naturais e zonas de recuperação ambiental.

A Unidade Geoambiental da Região da Borda do Planalto Basáltico (D) corresponde ao terceiro patamar do relevo desdobrado de cuestas, da borda ocidental da Bacia Sedimentar do Paraná, esculpido em litologias basálticas da Formação Serra Geral. No município de 
Bandeirantes esta unidade está quase que totalmente associada com Neossolos Litólicos Chernossólicos fragmentários, com substrato de basalto ( $90 \%)$ e com algumas ocorrências de Cambissolos Háplicos Tb Distróficos e Latossolos Vermelhos de granulometria fina. A maior parte das terras dessa unidade foi recomendada para conservação dos recursos naturais (40\%), ou seja, terras que ainda apresentam vegetação natural preservada ou para recuperação ambiental (23\%), quando estas terras já foram utilizadas e deveriam estar preservadas em função de aspectos ambientais ou legais. Neste caso, fatores como o elevado potencial natural de erosão, associado com a pequena profundidade efetiva dos solos e a capacidade de retenção de água moderada tornam a maior parte das terras desta unidade impróprias para a utilização agrícola sustentada.

As zonas recomendadas para pastagem perfazem $33 \%$ da área total desta unidade geoambiental e estão associadas com Cambissolos Háplicos Tb Distróficos e Neossolos Litólicos Chernossólicos fragmentários que ocorrem em declividades menores e, por conseguinte apresentam também menor potencial natural de erosão. As áreas recomendadas para agricultura intensiva e semi-intensiva somam apenas $4 \%$ da área da unidade e estão associadas com os Latossolos Vermelhos Distróficos de textura argilosa ou média, que em função das boas características físicas e do relevo onde ocorrem $(<8 \%)$, apresentam potencial natural de erosão baixo (ZAI) ou moderado (ZAS).

A Unidade Geoambiental Região dos Planaltos Rampeados (F) domina grande parte da porção centro-oriental do Estado Mato Grosso do Sul, aí incluída a maior parte do município de Bandeirantes. A principal característica dessa unidade é a homogeneidade morfoestrutural onde predominam as formas conservadas, pediplanadas nos topos, esculpidas em rochas do Grupo Bauru, e amplas formas dissecadas em interflúvios tabulares ao longo dos vales, onde o processo erosivo fluvial expôs os basaltos da Formação Serra Geral (Mato Grosso do Sul, 1989).

Com uma área de $2160 \mathrm{~km}^{2}$, que representa $69,3 \%$ da área total do município de Bandeirantes, as terras dessa Unidade Geoambiental estão associadas, principalmente com Latossolos Vermelhos Distróficos de textura média ou argilosa e Neossolos Quartzarênicos Distróficos, que cobrem grandes extensões de áreas com declives planos a ondulados. Em função do alto potencial natural de erosão, da baixa disponibilidade de nutrientes, da baixa a muito baixa capacidade de retenção de umidade, a maioria das terras desta unidade foram recomendadas para o uso com pastagens $(59,8 \%)$. As zonas recomendadas para uso agrícola intensivo $(8,1 \%)$ e as zonas recomendadas para o uso agrícola semi-intensivo $(28,5 \%)$ foram diferenciadas com base no potencial natural de erosão, que é maior nas zonas de uso semi-intensivo. As zonas recomendadas para conservação dos recursos naturais/recuperação ambiental perfazem apenas 3,6\% da área da unidade e estão associadas exclusivamente com áreas de preservação permanente localizada ao longo dos rios e áreas de nascentes.

\section{CONCLUSÕES}

O uso de geotecnologias permitiu a utilização de dados de atributos do terreno obtidos por métodos matemáticos, a realização de uma avaliação quali-quantitativa, além da análise integrada de dados ambientais, originais e secundários, de diferentes fontes e formatos possibilitando à estratificação do município em diferentes zonas agroecológicas com indicação de áreas passíveis de exploração agrícola sustentável, contribuindo como um importante instrumento de ordenamento territorial.

A metodologia adotada também possibilitou a incorporação de indicativos de produção, particularizadas por ambiente e por condições climáticas, além de permitir, no limite da escala cartográfica adotada, o delineamento e a indicação de terras com restrição legal de uso e a indicação de áreas de potencial natural de erosão empregando métodos quantitativos de análise.

As zonas agroecológicas recomendadas para o uso com lavouras (intensivas e semi-intensivas) totalizam aproximadamente $1.150 \mathrm{~km}^{2}$, o que equivale a $37 \%$ da área total do município, enquanto que zonas agroecológicas recomendadas para o uso com pastagens somam $1.658 \mathrm{~km}^{2}$, o equivalente a $53 \%$ da área total do município, face, as restrições de fertilidade natural e retenção de umidade apresentadas pelos solos desta zona agroecológica.

As zonas recomendadas para conservação dos 
recursos naturais totalizam $167 \mathrm{~km}^{2}(5,3 \%)$, enquanto que as recomendadas para recuperação ambiental somam menos de $143 \mathrm{~km}^{2}$ (4,7\%). Essas terras constituem áreas de potencial natural de erosão muito alto e/ ou que apresentam restrições legais de uso e/ou que já foram desmatadas. Embora, ocorram indistintamente em todas as Unidades Geoambientais predominam na Unidade Geoambiental Região da Borda do Planalto Basáltico em função do elevado grau de dissecação, da maior declividade, e do elevado potencial natural de erosão.

\section{REFERÊNCIAS}

AGAR, P. M.; DE PABLO, C. L.; PINEDA, F. D. Mapping the ecological structure of a territory: a case study in Madrid (Central Spain). Environmental Management, v.19, p. 345-357, 1995.

ALFONSI, R. R.; PINTO, H. S.; ZULLO JÚNIOR, J.; CORAL, G.; ASSAD, E. D.; EVANGELISTA, B. A.; LOPES, T. S. S.; MARRA, E.; BEZERRA, H. S.; HISSA, H. R.; FIGUEIREDO, A. F.; SILVA, G. G.; SUCHAROV, E. C.; ALVES, J.; MARTORANO, L. G.; BOUHID, A.; ROMÍSIO, G.; BASTOS ANDRADE, W. E. Zoneamento Climático da Cultura do Café (Coffea arabica) no Estado de Mato Grosso do Sul. Campinas: IAC: UNICAMP; Brasília: Embrapa Cerrados; Niterói: Pesagro-Rio; Rio de Janeiro: SIMERJ: Embrapa Solos; 2002. Disponível em: $<$ http://www. cpa.unicamp.br/cafe/MS_menu.html $>$. Acesso em: 03 nov. de 2006.

BARROS, M. A.; MOREIRA, M. A.; RUDORFF, B. F. T. Processo analítico hierárquico na identificação de áreas favoráveis ao agroecossistema cafeeiro em escala municipal. Pesquisa Agropecuária Brasileira, v.42, p.1769-1777, 2007.

BIRKELAND, P. W. Soils and Geomorphology. Revised edition of Pedology, Weathering and Geomorphological Research, first published in 1974. New York, Oxford: Oxford University Press. 1984. 372 p.
BRAIMOH, A. K.; VLEK, P. L. G.; STEIN, A. Land Evaluation for Maize Based on Fuzzy Set and Interpolation. Environmental Management, v.33, p. 226-238, 2004.

BRUNINI, O.; ZULLO JR., J.; PINTO, H. S.; ASSAD, E. D.; SAWAZAKI, E.; DUARTE, A. P.; PATTERNIANI, M. E. Z. Riscos climáticos para a cultura de milho no estado de São Paulo. Revista Brasileira de Agrometeorologia, v.9, p.519-526, 2001.

CALDERANO FILHO, B.; POLIVANOV, H.; GUERRA, A. J. T.; CHAGAS, C. S.; CARVALHO JUNIOR, W. Estudo geoambiental do município de Bom Jardim - RJ, com suporte de geotecnologias: subsídios ao planejamento de paisagens rurais montanhosas. Sociedade \& Natureza, v.22, p.55-73, 2010.

CARVALHO JUNIOR, W.; CHAGAS, C. S.; PEREIRA, N. R.; STRAUCH, J. C. M. Elaboração de zoneamentos agropedoclimáticos por geoprocessamento: soja em municípios do Rio Grande do Sul. Revista Brasileira de Ciência do Solo, v.27, p.379-387, 2003.

CHAGAS, C. S.; CARVALHO JUNIOR, W.; PEREIRA, N. R.; BHERING, S. B.; STEINMETZ, S. Um método para elaboração de zoneamentos agropedoclimáticos: estudo de caso do arroz irrigado no Rio Grande do Sul. Revista Brasileira de Agrometeorologia, v.9, p.571-580, 2001.

CHAGAS, C. S.; CARVALHO JUNIOR, W.; PEREIRA, N. R.; FERNANDES FILHO, E. I. Aplicação de um sistema automatizado (ALES - Automated Land Evaluation System) na avaliação das terras das microrregiões de Chapecó e Xanxerê, Oeste Catarinense, para o cultivo de grãos. Revista Brasileira de Ciência do Solo, v.30, p.509-522, 2006.

EMBRAPA. Centro Nacional de Pesquisa de Solos. Zoneamento agropedoclimático do Estado de Santa Catarina. Rio de Janeiro: Embrapa Solos, 2000. CD-ROM. 
EMBRAPA. Centro Nacional de Pesquisa de Solos. Sistema Brasileiro de Classificação de Solos. 2.ed. Rio de Janeiro: Embrapa Solos, 2006. 306p.

EMBRAPA. Centro Nacional de Pesquisa de Solos. Levantamento de reconhecimento de baixa intensidade dos solos do município de Bandeirantes - Zoneamento agroecológico do Estado do Mato Grosso do Sul. Rio de Janeiro: Embrapa Solos, 2009.

ENGEL, B. Estimating Soil Erosion Using RUSLE (Revised Universal Soil Loss Equation) Using ArcView. Purdue University, Department of Agricultural and Biological Engineering, West Lafayette, Indiana. 1999, 10 p.

FOOD AND AGRICULTURE ORGANIZATION OF THE UNITED NATIONS - FAO. La erosion del suelo por el água: algunas medidas para combatirla en las tierras de cultivo. Roma, 1967. 207p.

FOOD AND AGRICULTURE ORGANIZATION OF THE UNITED NATIONS - FAO. Zonificación agro-ecológica: guia general. Rome, 1996. 82p. (FAO. Boletin de Suelos, 73).

FOOD AND AGRICULTURE ORGANIZATION OF THE UNITED NATIONS - FAO. Agro-ecological zoning and GIS applications in Asia with special emphasis on land degradation assessment in drylands (LADA). REGIONAL WORKSHOP BANGKOK, Thailand, 2003. Proceedings AGL/MISC/38, FAO, Rome, 2005. 127p.

FOURNIER, R. Climate e erosion. Press Universitaires de France, Paris, 1960. 201p.

GALLANT, J. C. \& WILSON, J. P. Primary topographic attributes. In: WILSON, J. P. \& GALLANT, J. C. (Eds.). Terrain Analysis: Principles and applications. New York: John Wiley \& Sons, 2000. p.51-85.

GONÇALVES, A. O.; GACHET, G. F.; SILVA, C. A. M. Automação de algoritmo para caracterização climática de Köppen utilizando procedimentos computacionais. In: $14^{\circ} \mathrm{CONGRESSO} \mathrm{BRASILEIRO} \mathrm{DE}$ AGROMETEOROLOGIA, Campinas, 2005. Anais... Campinas, SBAGRO, 2005.
LOMBARDI NETO, F. Rainfall erosivity - its distribution and relationship with soil loss at Campinas, Brazil. Purdue University, West Lafayette, 1977. 53p. (Master of Science).

LOMBARDI NETO, F.; MOLDENHAEUR, W. C. Erosividade da chuva: sua distribuição e relação com perdas de solo em Campinas, SP. Bragantia, v.51, p.189-196, 1992.

MALUF, J. R. T.; CUNHA, G. R.; MATZENAUER, $\mathrm{R}$. Zoneamento de riscos climáticos para a cultura de milho No Rio Grande do Sul. Revista Brasileira de Agrometeorologia, v. 9, p.446-459, 2001.

MANNIGEL, A. R.; CARVALHO, M. P.; MORETI, D.; MEDEIROS, L. R. Fator erodibilidade e tolerância de perda dos solos do Estado de São Paulo. Acta Scientiarum, v. 24, p.1335-1340, 2002.

MARTORANO, L. G.; ANGELOCCI, L. R.; VETTORAZZI, C. A.; VALENTE, R. O. A. Zoneamento agroecológico para a região de Ribeirão Preto utilizando um sistema de informações geográficas. Scientia Agricola, v.56, p.739-747, 1999.

MATO GROSSO DO SUL. SECRETARIA DE PLANEJAMENTO E COORDENAÇÃO GERAL - SEPLAN-MS. Macrozoneamento geoambiental do Estado de Mato Grosso do Sul. Campo Grande, 1989. 242p.

RAMALHO FILHO, A.; BEEK, K. J. Sistema de avaliação da aptidão agrícola das terras. $3 \mathrm{ed}$. rev. Rio de Janeiro: EMBRAPA - Centro Nacional de Pesquisa de Solos, 1995. 65p.

ROSA, R. Geotecnologias na geografia aplicada. Revista do Departamento de Geografia, v. 16, p.8190, 2005.

SANS, L. M. A.; ASSAD, D.; GUIMARÃES, D. P.; AVELAR, G. Zoneamento de riscos climáticos para a cultura de milho na região centro-oeste do Brasil e para o estado de Minas Gerais. Revista Brasileira de Agrometeorologia, v. 9, p.527-539, 2001. 
SILVA, C. S.; ASSAD, E. D. Zoneamento de riscos climáticos para O ARROZ DE SEQUEIRO NOS ESTADOS DE Goiás, Mato Grosso do Sul, Minas Gerais, Tocantins e Bahia. Revista Brasileira de Agrometeorologia, v. 9, p.536-543, 2001.

SILVA, J. S. V.; CARVALHO, J. R. P.; SANTOS, R. F.; FELGUEIRAS, C. A. Zoneamentos ambientais: quando uma unidade territorial pode ser considerada homogênea? Revista Brasileira de Cartografia, v.59, p.83-92, 2007.

THORNTHWAITE, C.W. An approach toward a rational classification of climate. Geographical Review, v.38, p.55-94, 1948.

THORNTHWAITE, C. W.; MATHER, J. R. The water balance. Publications in Climatology. New Jersey: Drexel Institute of Technology, 1955. 104p.

VAN RANST, E.; TANG, H.; GROENEMANS, R.; SINTHURAHAT, S. Application of fuzzy logic to land suitability for rubber production in peninsular Thailand. Geoderma, v.70, p.1 -19, 1996.

WISCHMEIER, W. H.; SMITH, D. D. Predicting rainfall erosion losses: a guide to conservation planning. Washington, D.C.: USDA, 1978. 57 p.

YIZENGAW, T. \& VERHEYE, W. Application of computer captured knowledge in land evaluation, using ALES in central Ethiopia. Geoderma, v.66, p.297-311, 1995.

XAVIER-DA-SILVA, J. Geoprocessamento para Análise Ambiental. Rio de Janeiro. 2001. 227 p.

ZARONI, M. J.; ORTEGA, A.; PEREIRA, N. R.; CARVALHO JUNIOR, W.; AMARAL, F. C. S.; CHAGAS, C. S. Caracterização da erosividade das chuvas dos municípios de Bonito, Dourados, Jardim e Nioaque, Estado do Mato Grosso do Sul. In: $31^{\circ} \mathrm{CON}-$ GRESSO BRASILEIRO DE CIÊNCIA DO SOLO, Porto Alegre, 2007. Anais... Porto Alegre, Sociedade Brasileira de Ciência do Solo/UFRGS, 2007.
ZHANG, B.; ZHANG, Y.; CHEN, D.; WHITE, R. E.; LI, Y. A quantitative evaluation system of soil productivity for intensive agriculture in China. Geoderma, v.123, p.319-331, 2004. 